\title{
Detecting Iron-based Pigments on Ruthenium-coated Archaeological Pottery by SEM-EDS and by Micro-XRF-SEM
}

\author{
M. W. Pendleton ${ }^{1}$, D. K. Washburn ${ }^{2}$, E. A. Ellis ${ }^{3}$, and B. B. Pendleton ${ }^{4}$ \\ ${ }^{1}$ Microscopy and Imaging Center, Interdisciplinary Life Sciences Building, Mail Stop 2257, Texas \\ A\&M University, College Station, TX 77843-2257. \\ 2 American Section, University Museum, University of Pennsylvania, Philadelphia, PA 19104. \\ ${ }^{3}$ Microscopy Consulting Technologist, P.O. Box 6124, Thomasville, GA 31758. \\ ${ }^{4}$ Department of Agricultural Sciences, West Texas A\&M University, Box 60998, Canyon, TX \\ 79016-0001.
}

The identification of the elements contained in the paint applied to pottery at an archaeological site can be important in determining the site's cultural and temporal context. Using a JEOL JSM-6400 scanning electron microscope (SEM), (operating at $15 \mathrm{kV}$ and $15 \mathrm{~mm}$ working distance), secondary and backscatter images along with an energy dispersive spectroscopy (SEM-EDS) elemental map (Princeton Gamma Tech EDS detector) were produced of a ruthenium-coated [1] ancestral Pueblo black-on-white pottery sherd from the American Southwest. The black colored paint patterns on this sherd (Fig. 1) contained an iron-based pigment which, in secondary SEM mode (Fig. 2), comprised a conductive area that was focused due to the contact with aluminum foil, copper tape and carbon tape which provided a path to ground at the sherd's outside edges. The charging present in the unpainted and un-conductive sherd surface was modulated by the ruthenium coating, so that the bright charging effect in secondary SEM mode was confined to the unpainted areas of the sherd. This modulated charging effect facilitated the production of an elemental iron SEM-EDS map to be produced (Fig. 3) which traced the location of the iron pigment on the sherd. In this way, patterns of paint which are not visible on weathered or abraded sherds might be detected by secondary and backscatter SEM imaging and SEM-EDS mapping without resorting to coating the sherds with an evaporative carbon coating. While the application of a carbon coating facilitated the production of backscatter images along with SEM-EDS elemental iron maps of a piece of the same sherd used in this study [2 and 3], any pigment patterns of significant cultural importance were obscured by the carbon coating so that further visual study of these patterns would be difficult or impossible. The pigment pattern is still visible on the sherd in this study following ruthenium vapor coating (Fig. 1). This ruthenium coating modulated the charging effects to allow the production of Figs. 2 and 3.

The above discussion and images (Figs. 1-3) have been presented previously in publications [4 and 5] utilizing only SEM-EDS mapping and not Micro X-ray fluorescence (Micro-XRF-SEM). The same sherd discussed in publications [4 and 5] was also utilized to produce several Micro-XRF-SEM elemental maps (Fig. 4) using an X-ray source (IXRF Systems 10 micron X-beam Micro-XRF, $50 \mathrm{kV}$ ) along with a SEM (Hitachi S-3400N) with an IXRF Systems (30 mm) EDS detector. While the SEMEDS system could only produce an elemental map of iron, the IXRF Systems EDS detector was able to produce elemental maps of iron and of aluminum, potassium, calcium, sulfur, and silicon (Fig. 4). The greater number of elements detected by Micro-XRF-SEM is due to the lower background of XRF compared to the SEM beam in SEM-EDS. A charging effect does not occur with Micro-XRF-SEM mapping, so while no coating was required, ruthenium was applied for the comparison with SEM-EDS. 
Micro-XRF-SEM is more effective than SEM-EDS in locating trace elements in the paint pigment and matrix of ancestral Pueblo black-on-white pottery.

\section{References}

[1] EA Ellis and MW Pendleton, Microscopy Today 15 (2007), p. 44.

[2] M Pendleton et al., Microscopy Today 20 (2012), p. 32.

[3] M Pendleton et al., Yale Journal of Biology and Medicine, In Press.

[4] M Pendleton et al., G.I.T. Imaging and Microscopy 14 (2012), p. 30.

[5] M Pendleton et al., Microscopy and Microanalysis 18 (Suppl. 2) (2012), p. 1072.

[6] The authors acknowledge Kenny Witherspoon and Mandi Hellested of IXRF Systems for the MicroXRF-SEM analysis of the sherd and for sharing their scientific expertise. Figs. 1-3 reprinted with permission of Cambridge University Press from [5], (C) Microscopy Society of America 2012.
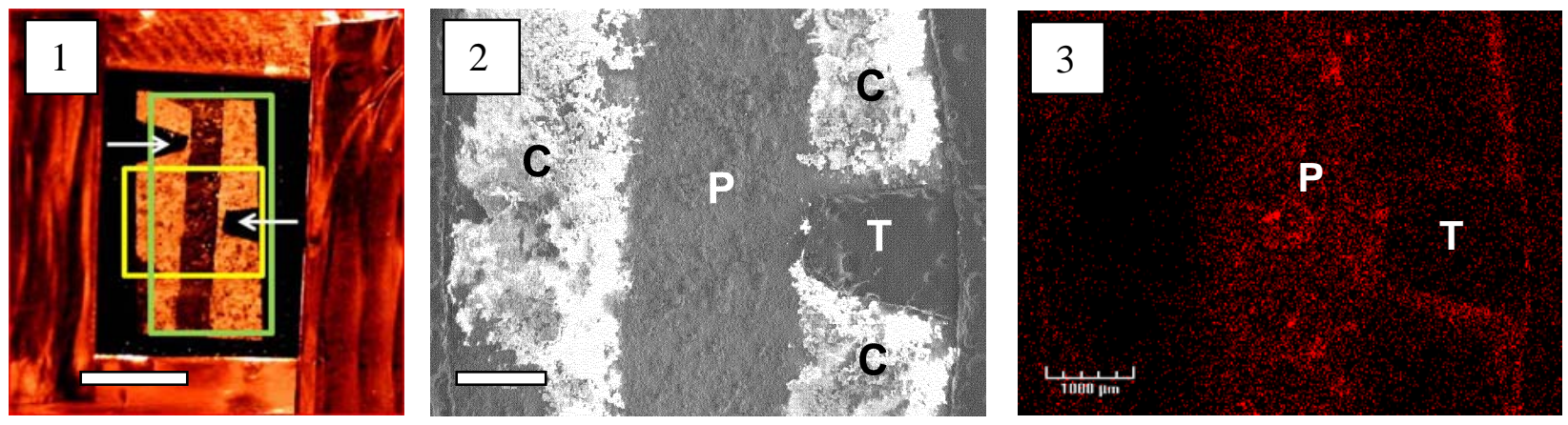

Figure 1. Light microscope image of ruthenium-coated sherd. No carbon coating applied to Figs. 1-4. Arrows $=$ carbon tape. Lighter yellow rectangle is area of images in Figs. 2-3. Darker green rectangle is area of images in Fig. 4 below. Scale bar $=5 \mathrm{~mm}$. Figure 2. Secondary SEM image of ruthenium-coated sherd. $\mathrm{C}=$ charging. $\mathrm{P}=$ paint. $\mathrm{T}=$ carbon tape. Scale bar $=1 \mathrm{~mm}$. Figure 3. EDS map of iron on ruthenium-coated sherd. $\mathrm{P}=$ paint. $\mathrm{T}=$ carbon tape. Scale bar $=1 \mathrm{~mm}$.

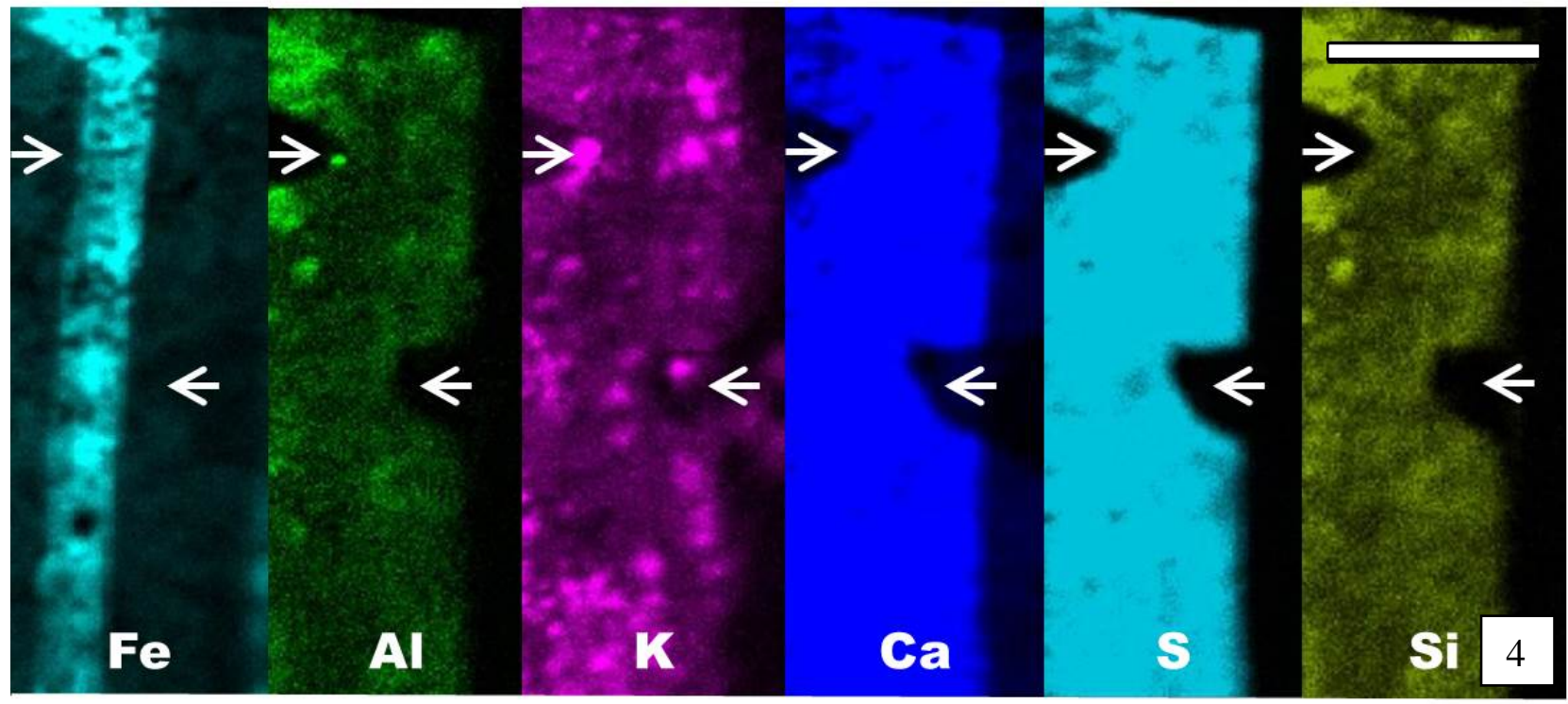

Figure 4. Micro-XRF-SEM elemental maps of ruthenium-coated sherd. Arrows = carbon tape. Fe = iron elemental map. $\mathrm{Al}=$ aluminum elemental map. $\mathrm{K}=$ potassium elemental map. $\mathrm{Ca}=$ calcium elemental map. $\mathrm{S}=$ sulfur elemental map. $\mathrm{Si}=$ silicon elemental map. Scale bar $=5 \mathrm{~mm}$. 